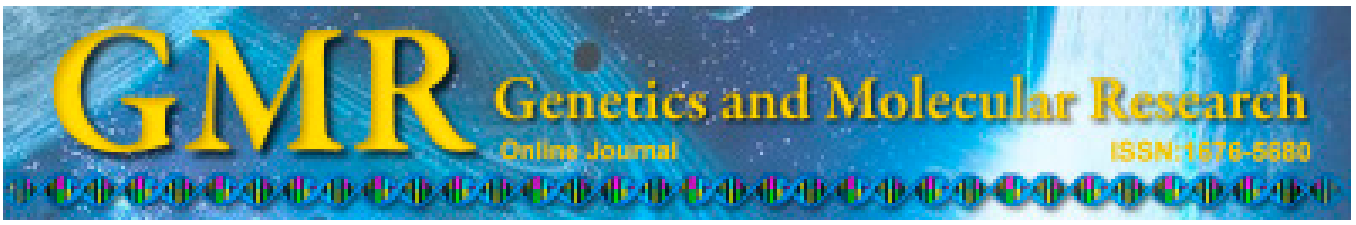

\title{
Genetic diversity and taxonomic status of Gymnocypris chilianensis based on the mitochondrial DNA cytochrome $b$ gene
}

\author{
J.P. Zhang ${ }^{1}$, Z. Liu ${ }^{1}$, B. Zhang ${ }^{2}$, X.Y. Yin ${ }^{2}$, L. Wang ${ }^{3}$, H.N. Shi ${ }^{1}$ and \\ Y.J. Kang ${ }^{1}$ \\ ${ }^{1}$ College of Animal Science and Technology, Gansu Agricultural University, \\ Lanzhou, China \\ ${ }^{2}$ The Fisheries Bureau of Jiuquan City in Gansu, Jiuquan, China \\ ${ }^{3}$ Gansu Agro-Ecological Environment Protection Agency, Lanzhou, China
}

Corresponding author: Z. Liu

E-mail: liuz@gsau.edu.cn

Genet. Mol. Res. 14 (3): 9253-9260 (2015)

Received November 3, 2014

Accepted April 27, 2015

Published August 10, 2015

DOI http://dx.doi.org/10.4238/2015.August.10.5

\begin{abstract}
In order to study the genetic diversity and taxonomic status of Gymnocypris chilianensis on a molecular level, the mitochondrial DNA cytochrome $b$ gene was sequenced for 74 individuals of $G$. chilianensis from two locations (Heihe River and Shule River) and 42 individuals of its affinis species Gymnocypris przewalskii. Analyses of genetic diversity and sequence differences were conducted for these samples, combined with the analysis of 30 homologous sequences of another affinis species Gymnocypris eckloni, which were downloaded from GenBank. The results showed that both the haplotype diversity $(h$ $=0.9820)$ and nucleotide diversity $(\pi=0.0039)$ of the Shule River $G$. chilianensis were lower than the other populations, thus, the Shule River G. chilianensis should be prioritized for protection because of its lower genetic diversity level. The results of sequence analysis showed that the genetic distance between the Heihe River G. chilianensis population and the Shule River G. chilianensis population was 0.0064, and the
\end{abstract}


genetic distance between these two populations and the G. przewalskii population was 0.0838 and 0.0810 , respectively. The genetic distance between the two G. chilianensis populations and the G. eckloni population was 0.0805 and 0.0778 , respectively. Analysis of sequence differences indicates that $G$. chilianensis is sufficiently diverged from G. przewalskii and G. eckloni to the extent that it has reached species level, thus, G. chilianensis can be considered an independent species of Gymnocypris.

Key words: Gymnocypris chilianensis; Cytochrome $b$; Genetic diversity; Taxonomic status

\section{INTRODUCTION}

Polymorphism analysis of mitochondrial DNA (mtDNA) is a powerful tool for research on conservation biology and evolutionary biology (Wilson et al., 1985). The structure and function of the cytochrome $b$ gene (Cyt $b$ ) is the most clearly understood among the 13 protein-coding genes of mtDNA. Because of its simple structure, bare recombination, and faster evolution speed, Cyt $b$ has been considered as one of the creditable molecular markers to solve problems on classification and phyletic evolution (Irwin et al., 1991), and it is widely used in the study of genetic diversity and interspecific or intraspecific phyletic evolution of vertebrates (Zhou et al., 2003; O’Bryan et al., 2010).

Gymnocypris chilianensis belongs to the genus Gymnocypris, the subfamily Schizothoracinae, and the family Cyprinidae. It is only distributed in inland river basins of the Hexi Corridor in China (Li et al., 1974; $\mathrm{Wu}$ and $\mathrm{Wu}, 1992$ ). The Hexi Corridor is located at the junction of the Loess Plateau, the Tibetan Plateau, and the Inner Mongolian Plateau. Depending on the quantity of rain and snow water from the Qilian Mountains, three inland rivers are formed, the Heihe River, the Shule River, and the Shiyang River, which become the main distribution areas of Gymnocypris in China. The source of the three inland rivers in the Hexi Corridor is an alpine glacier from the Qilian Mountains. Because of the attenuation of the function on climate regulation, precipitation, and water retention year by year, the water supply of inland river basin decreases continually, which intensifies the overbalance of ecological environment in the middle and lower reaches of inland rivers. Concurrently, a significant proportion of G. chilianensis habitat has been lost and its natural distribution area has been substantially reduced, as a result of factors such as artificial damming and new hydropower engineering. Influenced by both natural and artificial factors, the wild resource of G. chilianensis is declining sharply, and its genetic diversity is diminishing progressively.

Genetic diversity is the foundation for evolution and acclimatization of organisms. The more abundant the population genetic diversity is, the stronger the ability to adapt to environmental changes will be. Furthermore, a lack of genetic diversity is a great threat to organisms living in unbalanced ecological environments (Xiao et al., 2013). Therefore, in order to develop reasonable and efficient measures of resource conservation, it is necessary to study the genetic diversity and population structure of G. chilianensis. To date, only Zhao et al. (2011) have studied the phylogeography of G. chilianensis in the inland river basins of the Hexi Corridor in China, while other research on genetic diversity has not yet been 
reported.

Moreover, there are always disagreements on the taxonomic status of G. chilianensis, and the taxonomic results based on morphology by several researchers have differed ( $\mathrm{Wu}$, 1964; Li et al., 1974; Zhao, 1986). In this research, we analyzed the genetic diversity of $G$. chilianensis and its genetic relationship with Gymnocypris eckloni and Gymnocypris przewalskii, by focusing on G. chilianensis and using the Cyt $b$ gene as a marker and G. eckloni and $G$. przewalskii as controls, with the aim of providing a theoretical basis for resource conservation and phyletic classification of G. chilianensis.

\section{MATERIAL AND METHODS}

\section{Material}

A total of 74 individuals of $G$. chilianensis were collected, of which 44 individuals were collected from the Heihe River and 30 individuals from the Shule River, and 42 individuals of G. przewalskii were collected from the Qinghai Lake [permit No. (Gan) SYXF (2010) 12, issued by the government of Gansu Province). The sampling information is shown in Figure 1. Part of the caudal fin was cut from each specimen after all specimens were identified to species level based on external characteristics, and then preserved in $95 \%$ ethanol and stored at $-20^{\circ} \mathrm{C}$. An additional $30 \mathrm{Cyt} b$ sequences of $G$. eckloni were downloaded from the GenBank database, of which the specimens were derived from the mainstream of the Yellow River in Qinghai Province, China.

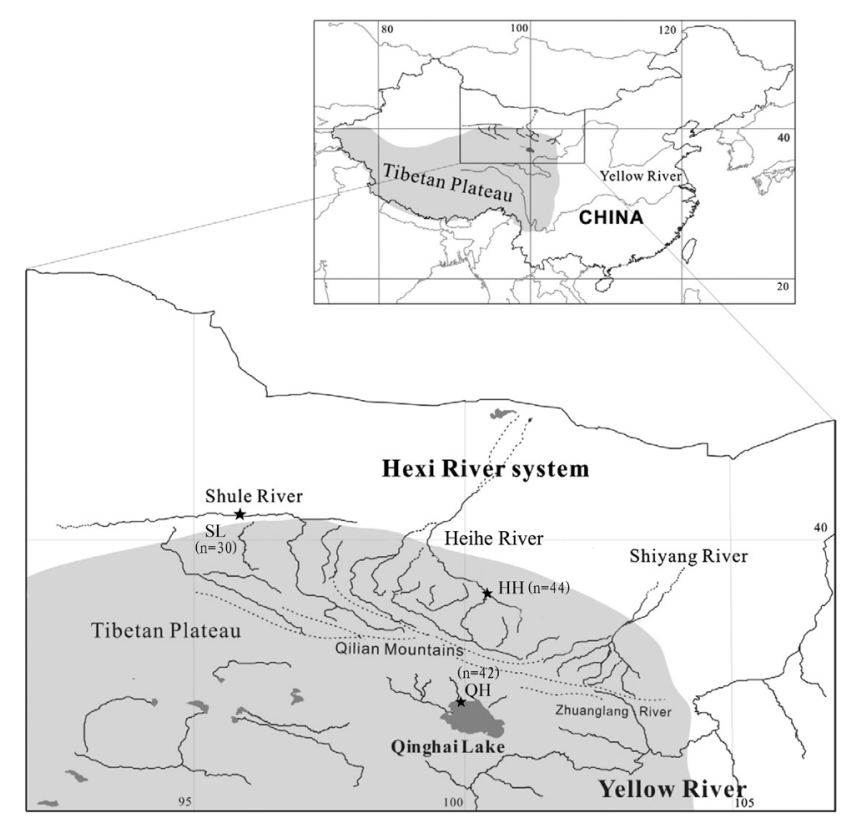

Figure 1. Sampling locations, sample size, and sample codes of Gymnocypris populations in China. $\mathrm{HH}=$ Heihe River Gymnocypris chilianensis; $\mathrm{SL}=$ Shule River G. chilianensis; and $\mathrm{QH}=$ Qinghai Lake Gymnocypris przewalskii. 


\section{DNA extraction and polymerase chain reaction (PCR)}

Genomic DNA was extracted by the routine method of phenol-chloroform extraction (Green and Sambrook, 2012). The sequences of the primers are as follows: F5'CTCCGATCTCCGGATTACAAGAC-3' and R5'-GACTTGAAAACCACCGTTG-3'. The PCR amplification was performed in a total volume of $50 \mu \mathrm{L}$ containing 50 ng template DNA, 2.5 mM 1X PCR Buffer, 1 U Taq DNA polymerase (Takara, Dalian, China), $100 \mu \mathrm{M}$ dNTPs (Takara), $0.4 \mu \mathrm{M}$ of each primer, and $19.3 \mu \mathrm{L} \mathrm{ddH_{2 }} \mathrm{O}$. The PCR amplification was carried out under the following conditions: initial denaturation at $95^{\circ} \mathrm{C}$ for $3 \mathrm{~min}, 30$ cycles consisting of $94^{\circ} \mathrm{C}$ for $30 \mathrm{~s}, 54^{\circ} \mathrm{C}$ for $30 \mathrm{~s}$, and $72^{\circ} \mathrm{C}$ for $90 \mathrm{~s}$, and a final extension at $72^{\circ} \mathrm{C}$ for $10 \mathrm{~min}$.

\section{Cloning and sequencing}

The PCR product was purified with the Universal DNA Purification Kit (TianGen, Beijing, China), then cloned into the pMD19-T vector (Takara). The recombinant plasmid was introduced into the Escherichia coli DH5 $\alpha$ strain (TianGen). After being selected by LacZ blue-white selection and identified by double digestion with EcoRI and PstI, the positive clones were sequenced by bi-directional DNA sequencing (Sangon Biotech, Shanghai, China).

\section{Statistical analysis}

The original data of the sequences were obtained using the Chromas 1.45 software (http://www.technelysium.com.au), aligned using the ClustalX 1.83 program (http://www. clustal.org/) with default parameters and 1000 bootstraps, and checked by eye. Polymorphic sites, number of haplotypes, haplotype diversity index $(h)$, and nucleotide diversity index $(\pi)$ were calculated using the DnaSP v5 software (http://www.ub.edu/dnasp/). Base composition and genetic distance among the four populations (the average genetic distances based upon Kimura's two-parameter model) were calculated using the MEGA 5.0 software (http://www. megasoftware.net/). Gymnodiptychus pachycheilus (GenBank accession No. JQ082349) and Ptychobarbus dipogon (GenBank accession No. JQ082345) were taken collectively as the out-group. The distance matrix of Kimura's two-parameter model was used during the analysis. The phylogenetic tree was created using the neighbor-joining method (NJ), and statistical support was estimated using 1000 bootstrap replicates.

\section{Nucleotide sequence accession Nos.}

The Cyt $b$ partial sequences newly defined in the current study have been deposited in the GenBank database under the accession No. KM371119-KM371228.

\section{RESULTS}

\section{Gene mutation}

A total of 146 homologous sequences of $1140 \mathrm{bp}$ were used for the analysis of genetic 
diversity and gene mutations, and a total of 336 polymorphic sites were detected, accounting for $29.5 \%$ of the total analyzed sites, including 266 transitions and 70 transversions. The transition/transversion ratio was 3.8, which was significantly higher than 2.0 and showed that the mutagenesis was not saturated, and weighted analysis was not needed in the phylogenetic analysis (Knight and Mindell, 1993). The nucleotide content averaged 30.9\% T, 26.5\% C, $26.1 \% \mathrm{~A}$, and $16.5 \% \mathrm{G}$, showing obvious G-reversed bias. The content of $\mathrm{G}+\mathrm{C}(43 \%)$ was less than $\mathrm{A}+\mathrm{T}(57 \%)$, showing the common characteristic of the Cyt $b$ gene (Su et al., 2014).

\section{Genetic diversity}

A total of 132 haplotypes were recovered from 146 aligned sequences and the haplotype diversity and nucleotide diversity indices are shown in Table 1 . The haplotype diversity of the Heihe River $G$. chilianensis population was the highest $(h=1.0000)$, compared with the lowest haplotype diversity of the Shule River $G$. chilianensis $(h=0.9820)$. While the nucleotide diversity of $G$. eckloni was the highest $(\pi=0.0067)$, compared with the lowest nucleotide

\section{Table 1. Genetic diversity indices of the four Gymnocypris populations studied.}

\begin{tabular}{lcccc}
\hline Population & No. of haplotypes & No. of polymorphic sites & Haplotype diversity $(h)$ & Nucleotide diversity $(\pi)$ \\
\hline HH & 44 & 116 & 1.0000 & 0.0057 \\
SL & 27 & 63 & 0.9820 & 0.0039 \\
QH & 37 & 105 & 0.9930 & 0.0055 \\
HB & 24 & 40 & 0.9840 & 0.0067 \\
Total & 132 & 336 & 0.9980 & 0.0414 \\
\hline
\end{tabular}

HH = Heihe River Gymnocypris chilianensis; $\mathrm{SL}=$ Shule River G. chilianensis; $\mathrm{QH}=$ Qinghai Lake Gymnocypris przewalskii; and $\mathrm{HB}=$ Yellow River Gymnocypris eckloni.

diversity of Shule River $G$. chilianensis $(\pi=0.0039)$.

\section{Genetic differentiation}

Genetic distance within and among populations was estimated using the Kimura's two-parameter model, with values ranging from 0.0039 to 0.0068 and from 0.0064 to 0.0838 , respectively (Table 2), suggesting that the genetic distances within populations were higher than among populations. The lowest genetic distance was observed between the Heihe River G. chilianensis population and the Shule River G. chilianensis population (0.0064), followed by the genetic distance between the G. przewalskii population and the G. eckloni population

Table 2. Genetic distance between the four Gymnocypris populations (below diagonal), genetic distance within populations (bold values at diagonal), and standard error (above diagonal).

\begin{tabular}{lcccr}
\hline Population & HH & SL & QH & HB \\
\hline HH & $\mathbf{0 . 0 0 6 1}$ & 0.0017 & 0.0056 & 0.0055 \\
SL & 0.0064 & $\mathbf{0 . 0 0 3 9}$ & 0.0054 & 0.0053 \\
QH & 0.0838 & 0.0810 & $\mathbf{0 . 0 0 5 5}$ & 0.0019 \\
HB & 0.0805 & 0.0778 & 0.0079 & $\mathbf{0 . 0 0 6 8}$ \\
\hline
\end{tabular}

$\mathrm{HH}=$ Heihe River Gymnocypris chilianensis; SL = Shule River G. chilianensis; QH = Qinghai Lake Gymnocypris przewalskii; and $\mathrm{HB}=$ Yellow River Gymnocypris eckloni. Bold numbers at diagonal represent the genetic distance within per Gymnocypris population. 
(0.0079), while the highest genetic distance was observed between the Heihe River G. chilianensis population and the G. przewalskii population (0.0838).

\section{Phylogenetic analysis}

The phylogenetic analysis showed that 132 haplotypes diverged into two main branches. One main branch contains the Heihe River $G$. chilianensis and the Shule River $G$. chilianensis, while the other branch contains G. przewalskii and G. eckloni. Bootstrap values

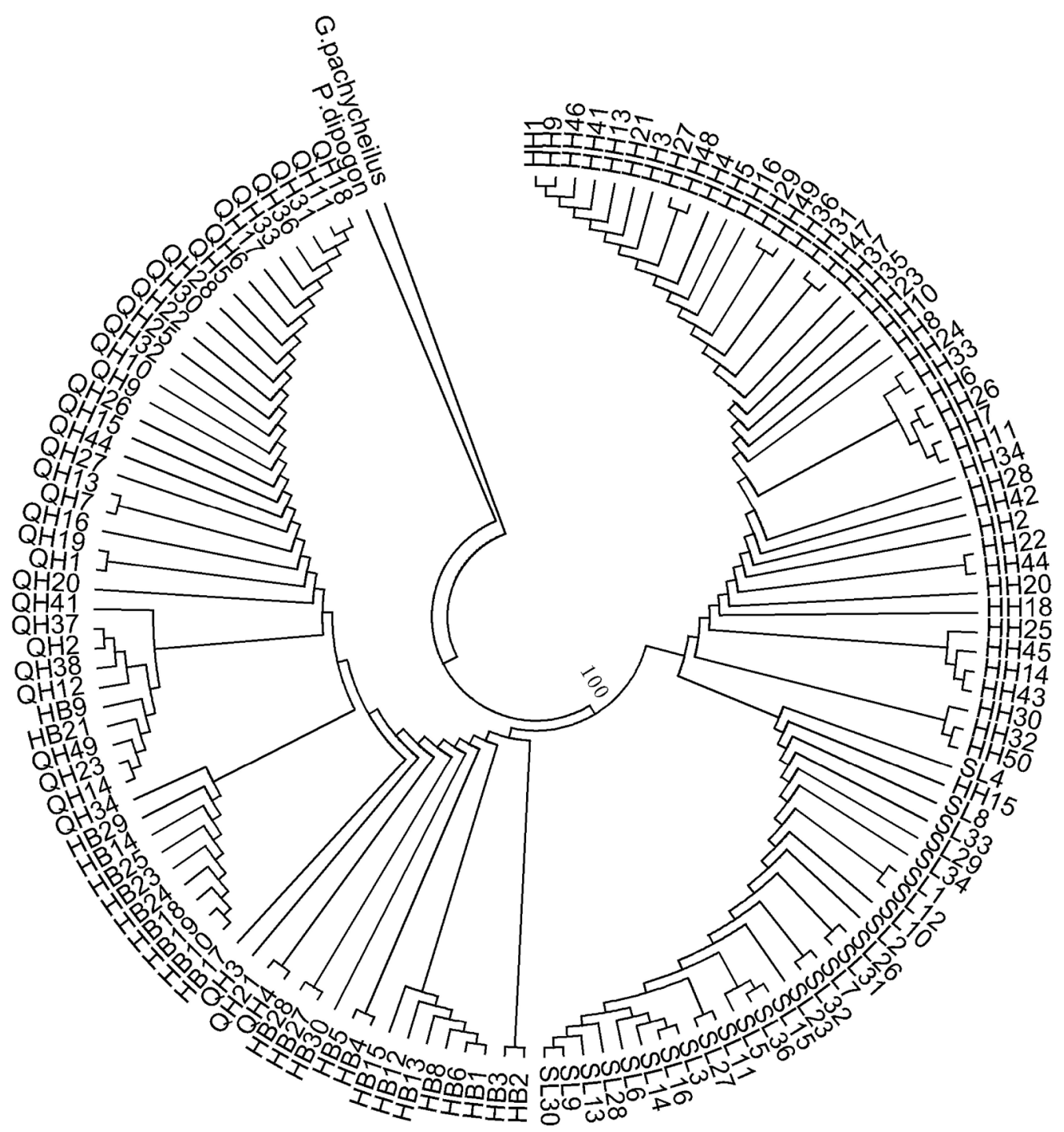

Figure 2. Neighbor-joining phylogenetic tree constructed from the 132 Cyt $b$ haplotypes from the Gymnocypris populations. $\mathrm{HH}=$ Heihe River Gymnocypris chilianensis; $\mathrm{SL}=$ Shule River G. chilianensis; $\mathrm{QH}=$ Qinghai Lake Gymnocypris przewalskii and $\mathrm{HB}=$ Yellow River Gymnocypris eckloni. 
were $100 \%$ (Figure 2).

\section{DISCUSSION}

The nucleotide diversity index is a significant indicator used to estimate the genetic variation of populations, where the value indicates the abundance or scarcity of the genetic diversity of a population. The nucleotide diversity index of the Shule River G. chilianensis population was 0.0039 , which was lower than the other populations in our study, but much higher than the result of research on the Shule River G. chilianensis $(\pi=0.0002)$ by Zhao et al. (2011). As a consequence, the Shule River G. chilianensis population should be prioritized for protection, considering its lower genetic diversity $(\pi<0.0047)$ according to the range of the nucleotide diversity index, which was proposed by Lan and Shi (1993) to estimate genetic diversity. Moreover, the combination of high haplotype diversity $(h=0.9820)$ with low nucleotide diversity $(\pi=0.0039)$ of the Shule River $G$. chilianensis population reveals the possible mechanisms for the formation of this population, which rapidly derived from a small effective population (Avise, 2000), similar to the research by Yang et al. (2008) on Anabarilius grahami.

According to $\mathrm{Wu}$ (1964), differences in the morphological traits exist between the scaleless carp of the Hexi region and G. eckloni from the Yellow River, based on the lower number of gill rakers, wider hypopharyngeal bone, and wider pupil diameter. Morphological classification has shown that the scaleless carp of the Hexi region, which was named $G$. chilianensis, is an independent species of Gymnocypris (Li et al., 1974). The species status of G. chilianensis was confirmed by Zhang et al. (2013) using the Cyt $b$ gene sequence. However, Zhao (1986) suggested that G. chilianensis should be classified as a subspecies of G. eckloni from the Yellow River, considering the less obvious morphological variation of Gymnocypris as the habitat approaching. For years, several studies of vertebrates, using the Cyt $b$ gene as a molecular marker, showed that the intraspecific sequence difference ranged from 0 to 0.0406 , with differentiation of species appearing obvious in individuals where the sequence difference was greater than 0.0600 (Xuegan et al., 2002; He et al., 2012). In our research, the genetic distances of the Cyt $b$ sequence between the Heihe River G. chilianensis population and the G. przewalskii and G. eckloni populations were 0.0838 and 0.0805 , respectively. The genetic distance of the Cyt $b$ sequence between the Shule River G. chilianensis population and the G. przewalskii and G. eckloni populations were 0.0810 and 0.0778 , respectively. All genetic distances were greater than 0.0600 , indicating that the genetic relationship between G. chilianensis and G. przewalskii and G. eckloni is distant, implying that the differentiation has reached species level. The NJ phylogenetic tree showed that the two populations of $G$. chilianensis cluster on one branch, which then clusters with G. eckloni and G. przewalskii, with bootstrap values of $100 \%$. Therefore, we suggest that G. chilianensis is an independent species, the view that is widely accepted (Wu, 1964; Li et al., 1974; Zhang et al., 2013), but different from the view of G. chilianensis as a subspecies of $G$. eckloni put forward by Zhao (1986). We also found that the genetic distance between G. przewalskii and G. eckloni was 0.0079 , a differentiation that has not reached the species level. The NJ phylogenetic tree showed that G. przewalskii and G. eckloni clustered together, forming one branch, but without forming a monophyletic group. As a consequence, G. przewalskii is thought to a subspecies of G. eckloni, however, further study is required.

\section{Conflicts of interest}




\section{The authors declare no conflict of interest. ACKNOWLEDGMENTS}

Research supported by the Project of Agro-Ecological Environment Protection of Gansu Province, China. The authors alone are responsible for the content and writing of the article.

\section{REFERENCES}

Avise JC (2000). Phylogeography: The history and formation of species. Harvard University Press, Cambridge.

Green MR and Sambrook J (2012). Molecular cloning: A laboratory manual. 4th edn. Cold Spring Harbor Laboratory Press, New York.

He Y, Zhou CQ, Liu GK, Chen L, et al. (2012). Research on the validity of Eospalax smithi inferred from molecular and morphological evidences. Acta Zootaxonomica Sinica 37: 36-43.

Irwin DM, Kocher TD and Wilson AC (1991). Evolution of the cytochrome $b$ gene of mammals. J. Mol. Evol. 32: 128-144.

Knight A and Mindell DP (1993). Substitution bias, weighting of DNA sequence evolution, and the phylogenetic position of Fea's Viper. Syst. Biol. 42: 18-31.

Lan H and Shi LM (1993). The origin and genetic differentiation of native breeds of pigs in southwest China: an approach from mitochondrial DNA polymorphism. Biochem. Genet. 31: 51-60.

Li SZ, Zhang SY and Shi Y (1974). Two new species and one new subspecies of fishes from the northern part of Gansu Province, China. Curr. Zool. 20: 414-419.

O'Bryan DM, Xie Z, Wang Y, Du J, et al. (2010). Phylogeography and conservation genetics of Lake Qinghai scaleless carp Gymnocypris przewalskii. J. Fish Biol. 77: 2072-2092.

$\mathrm{Su}$ JH, Ji WH, Wang J, Gleeson DM, et al. (2014). Phylogenetic relationships of extant zokors (Myospalacinae) (Rodentia, Spalacidae) inferred from mitochondrial DNA sequences. Mitochondrial DNA 25: 135-141.

Wilson AC, Cann RL, Carr SM, George M, et al. (1985). Mitochondrial DNA and two perspectives on evolutionary genetics. Biol. J. Linnean Soc. 26: 375-400.

Wu XW (1964). Ichthyography of Cyprinidae in China. Shanghai Science and Technology Press, Shanghai.

Wu YF and Wu CZ (1992). The fishes of the Qinghai-Xizang Plateau. Sichuan Publishing House of Science and Technology, Chengdu.

Xiao TQ, Lu CY, Li C, Zhang MZ, et al. (2013). Genetic diversity and phylogenetic analysis of eight Cyprinoid aquaculture breeds based on mitochondrial Cyt $b$ gene. J. Fisheries China 37: 344-350.

Xuegan Y, Yiguan W, Kaiya Z and Zhongguan L (2002). Authentication of oviductus ranae and its original animals using molecular marker. Biol. Pharm. Bull. 25: 1035-1039.

Yang B, Chen XY and Yang JX (2008). Structure of the mitochondrial DNA control region and population genetic diversity analysis of Anabarilius Grahami (Regan). Zool. Res. 29: 379-385.

Zhang YP, Du YY, Lou ZY and Wang T (2013). Molecular phylogeny of Schizothoracinae fishes in Gansu Province based on mitochondrial Cytochrome $b$ gene sequences. J. Northwest Normal Univ. 49: 91-96.

Zhao K, Duan Z, Peng Z, Gan X, et al. (2011). Phylogeography of the endemic Gymnocypris chilianensis (Cyprinidae): sequential westward colonization followed by allopatric evolution in response to cyclical Pleistocene glaciations on the Tibetan Plateau. Mol. Phylogenet. Evol. 59: 303-310. 